\title{
Sustainable packaging: an evaluation of crates for food through a life cycle approach
}

\author{
Adriana Del Borghi ${ }^{1}$ (D) Sara Parodi ${ }^{1} \cdot$ Luca Moreschi $^{1} \cdot$ Michela Gallo $^{1}$ \\ Received: 14 February 2020 / Accepted: 16 August 2020 / Published online: 26 August 2020 \\ (C) The Author(s) 2020
}

\begin{abstract}
Purpose The packaging system plays an essential role in the logistic chain and takes into account the rise in packaging demand and consumption. A study on sustainability was carried out through a comparative life cycle assessment in order to quantify and compare the environmental impacts of plastic, corrugated board and wood (solid, MDF and particleboard) crates used for food delivery. Single-use and multi-use systems were considered and compared.

Methods According to ISO 14040 and ISO 14044, the whole life cycle of crates was divided into four primary phases: raw materials acquisition, crate manufacturing, transport (including the reuse, if applicable) and final disposal. The functional unit used for this study was 1 crate with an external dimension of $400 \times 600 \times 240 \mathrm{~mm}$ and with an inner volume of 501 . The comparison focused on the critical parameters expected to have a higher influence on the results, such as the distances for delivery and the number of reuses for multi-use crates. All input data came from sector studies, literature and Ecoinvent database. The results were evaluated according to 8 impact categories. Two sensitivity analyses were performed.

Results and discussion The most relevant impacts are linked to transport, electricity and raw materials contributions. Cumulative energy demand results show that the renewable energy resources in the case of plastic crates are about $3 \%$ while for the other type of crates exceed the $30 \%$ reaching the $77.5 \%$ in the case of solid wood crate. The environmental impacts result lower for multiuse plastic crate due to its possibility of being reused during its lifetime, avoiding the high impacts of the manufacturing. The best option among the single-use systems is the solid wood crate. The final results of the sensitivity analysis applied to the transport distances show that the impacts related to solid wood are more stable than plastic. Concerning the end-of-life scenarios, a significant decreasing (around 14.7\%) in the global warming potential can be reached increasing the crates recycling till $100 \%$. Conclusions and recommendations The best crate materials are plastic crates if a recovery system is planned; otherwise, the best choice is the wood crate. It is preferable to use raw material, such as solid wood than processed material, such as particle board, MDF and corrugated board. In performing this type of analysis, it is important to have accurate data, preferentially primary data, in particular for plastic crates as evidenced by the sensitivity analysis.
\end{abstract}

Keywords Crates $\cdot$ Food packaging $\cdot$ Life cycle

Adriana Del Borghi

adriana.delborghi@unige.it

Sara Parodi

sara.parodi92@gmail.com

Luca Moreschi

luca.moreschi@edu.unige.it

Michela Gallo

michela.gallo@unige.it

1 DICCA - Department of Civil, Chemical and Environmental Engineering, University of Genoa, Via all'Opera Pia 15, 16145 Genova, Italy

\section{Introduction}

The relationships between environmental impacts and rise of the world population are clear and the numerous environmental and social problems have emphasized the concept of sustainability (Dobon et al. 2011a). Since the earliest times, in a changing world, a reflection on the food we consume has focused the attention on delivering sufficient and nutritious food in an environmentally sustainable way. In the supply chain of food, the packaging is clearly involved with the aim to reduce the environmental impacts and the waste production. Packaging is one of the most relevant waste sources: only in Europe, in 2008, 81.5 million tons of packaging waste has 
been generated (Eurostat 2017). Traditional food packaging is meant for mechanical supporting of otherwise non-solid food and protecting food from external influences (Gordon L. Robertson 2012). This principal function of packaging involves delay in the deterioration or spoilage processes, extension of shelf-life and maintenance of quality and safety of packaged food (Restuccia et al. 2010).

Food packaging is an evolving area, due to the introduction of new food technologies, a continuous change in the consumption habits and lifestyle and environmental influences. Today there are many campaigns promoting an environmentally sustainable food packaging, the so-called green packaging has the target to pollute as little as possible, not only food but also the environment, after use.

Eco-friendly packaging design and management, especially in sectors where packaging is necessary for product handling and transportation, have become a challenge (Accorsi et al. 2014). Traditional food packaging is meant for containment and protection before food products can be moved from one place to another (Gordon L. Robertson 2012). Over time, food packaging has been subjected to a great change and evolution, and a new perspective has emerged: quality, safety, convenience and communication are other interconnected functions (Dobon et al. 2011a). To satisfy industry requirements and consumer needs, maintaining food safety and reducing environmental impacts are the most relevant goals of food packaging (Marsh and Bugusu 2007). In this perspective, it is important to analyze food packaging with a comprehensive approach and test if packaging reduction and a shift to alternative materials and/or technologies allowing environmental improvements in packaging production may negatively affect the overall product system, e.g. by increasing food losses (Licciardello 2017).

Preserving natural resources, limiting the amount of produced waste, reducing polluting emissions and, in general, paying more attention to environmental protection in all stages of the production process are become specific objectives to be achieved. The protection and promotion of the health of consumers and of the environment are relevant aspects of the EU policies and the recent European legislation regarding packaging is certainly going in this direction. At the Union level, the EU Framework Regulation EC 1935/2004 regulates food contact materials (European Parliament 2004), whereas the guiding principles of Directive 94/62/EC of European Parliament and Council guide the reduction of packaging waste material as well as reuse (European Parliament 1994), recycling and energy recovery of packaging. In particular, the packaging waste directive sets out the following targets, specific for each material: a minimum of $60 \%$ recovery rate (including waste incineration); between 55 and $80 \%$ by weight of packaging waste to be recycled; with minimum rates of $60 \%$ by weight for glass, paper and cardboard; $50 \%$ by weight for metals; $22.5 \%$ by weight for plastics; and $15 \%$ by weight for wood (Eurostat 2017). Moreover, the Integrated Product Policy (IPP) aims to limit the environmental impact caused by the products in some way. The IPP, in a life cycle perspective, analyzes the product in each phase of his life, from cradle to grave, including the extraction of raw material and its processing, product manufacturing, distribution, recovery and final disposal. Policymakers want to promote sustainable production and consumption and, as a consequence, a great interest to provide environmental information of environmentally friendly products is growing up (Ibáñez-Forés et al. 2016). This environmental awareness is reflected in the necessity of modernization of the production cycles, caring also the impact that the finished product will have on the environment during their entire life cycle. Among the possible measures aimed at reducing the environmental impact of production cycles, there are precisely those related to the choice of type of material for packaging and its management during all the life cycle.

Life cycle assessment (LCA) methodology has been widely used to implement a study to assess the environmental performance of different kinds of food packaging (Dobon et al. 2011a). There are extended references to scientific literature where different materials were analyzed and compared, such as glass (Del Borghi et al. 2016), plastic (Humbert et al. 2009), metals (Detzel and Mönckert 2009) and cardboard (von Falkenstein et al. 2010), including several varieties of foods, such as meat (Dobon et al. 2011b), fruits and vegetables (Del Borghi et al. 2014; Robertson et al. 2014) and beverages (Hanssen et al. 2007).

In the field of plastic packaging, several studies have been made also assessing the comparison among traditional fossil fuel-based materials and emerging biopolymers (Blanco et al. 2020). The application of material reduction principles and recycled raw materials usually represent valuable opportunities for the reduction of environmental impacts for packaging products (Siracusa et al. 2014), but the substitution of fossil materials with biopolymers do not always offer the expected results. Ingrao et al. (2015a) performed an LCA of foamy polystyrene (PS) trays used for fresh meat packaging, highlighting how changes in the supply chain cannot be sought and how energy-shifting towards renewable resources represents the only viable solution for environmental improvements. The comparison of foamy polystyrene (PS) trays with foamy polylactic acid (PLA) trays showed that the use of primary PLA-i.e. not derived by waste materials - cannot guarantee a significant improvement in the environmental performance of the packaging material as the main impacts come from production and transportation of the granules (Ingrao et al. 2017). Moreover, if the transport system is not properly chosen by the producer and it is correctly assessed in the LCA study, the environmental impacts of PLA packaging could worsen the ones of traditional plastic materials (Ingrao et al. 2015b). 
Despite several studies were carried out on the sustainability of the packaging system because of the essential role in the logistic chain, LCA calculation rules and system boundaries are not harmonized thus affecting results comparability. Different critical issues can therefore occur during the comparison as standard LCA methodology does not set requirements in a mandatory way, nor it specifies rules for each single phase of the life cycle (Arena et al. 2003). To overcome this issue, several LCA-based tools were developed to optimize and/or to communicate the environmental performance of products, e.g. through environmental labels and Environmental Product Declaration (EPD) according to ISO 14025 standard (Del Borghi 2013; Magrassi et al. 2016).

In the context of Type III Environmental Labels, to ensure comparability, an LCA shall be performed according to specific requirements commonly set at international level. These requirements, defined as Product Category Rules (PCRs), are detailed rules used for the analysis of a product system by the LCA methodology, defining the functional unit, the system boundaries, the data quality, the impact categories to be considered, etc. (Del Borghi et al. 2008; Strazza et al. 2013). In the framework of the International EPD® System, based on the present study, the authors developed and published the first PCR for crates for food (PCR 2018:02 2018).

Anyhow, in this general framework, crates for food transport are not so deeply studied and assessed as other products for the food packaging have been. In literature, there are only a few publications that take in consideration that kind of packaging, and fewer present a comparison among different materials, usually plastic and cardboard (Albrecht et al. 2013; Koskela et al. 2014; Abejón et al. 2020).

Due to the lack of scientific literature on this specific type of packaging, this study could be considered the first of its kind as it uses a life cycle approach to evaluate different types of crates for food and covers all dominantly crate material typologies delivered to the market. The main goal of this study is to analyze and compare different types of crates in the food supply chain, assessing their environmental performances through LCA. With respect to the existing literature, the environmental impacts of different types of wood crates are assessed and compared with those of cardboard and plastic crates, also applying more peculiar impact categories. Moreover, the characterization of transport phasesidentified as one of the more crucial steps for other packaging products - is improved according to new primary data from trade associations.

After a deep research on data availability and reliability, five different materials were investigated specifically plastic, corrugated board, solid wood, MDF and particle board. Different systems were considered as well, such as single-use and multi-use systems, applied to disposable and reusable crates, respectively. Inventory data were collected from companies and the trade association or from Ecoinvent database (Wernet et al. 2016). The environmental performance of these alternatives was assessed in relation to global impacts - such as climate change or energy demand, commonly applied in most of LCA studies - and to regional and local impacts - such as the human or environmental toxicity potentials. The selection of impact categories was made in accordance with sector trade associations, thus highlighting relevant impacts for food packaging products as defined in the PCR for crates for food.

Furthermore, critical parameters were identified through an accurate sensitivity analysis in order to understand how possible improvements can be planned to enhance the sustainability of this type of packaging.

\section{Methods}

The LCA methodology according to ISO 14040-44 standards (ISO 2006a, b) was applied to quantify the environmental impacts associated with the crates' life cycle from a "cradle to grave" perspective.

The following different typologies of crates and materials were assessed:

1. Reusable plastic crate

2. Not reusable plastic crate

3. Corrugated board crate

4. Solid wood crate

5. MDF crate

6. Particle board crate

The requirements of the PCR for crates for food were followed to ensure comparability among products having the same function. Specific details are summarized in the subchapters below.

\subsection{Goal and scope definition}

The goal of this study is to quantify, evaluate and compare the environmental impacts of the production, transport, use and disposal of crates made up of different food contact materials. Corrugated cardboard, solid wood, particle board, MDF and plastic crates were compared, considering both one-way and multi-way systems where applicable. Moreover, the authors aim to identify the critical parameters in the case of multi-use crates (e.g. washing frequency and lifespan) and a multi-scenario of packaging end-of-life (EoL). The intended audience is decision makers, customers, retailers and stakeholders along the supply chain. 


\subsection{Functional unit}

The functional unit (FU) shall be consistent with the goal and scope of the study. The function of the systems under study is the food transport and in the case of crate, different sizes and different transported contents are involved in the analyzed system. To overcome these issues, a "standard crate" size and capacity for any different material types was set, considering an external dimension of $600 \times 400 \times 240 \mathrm{~mm}$ and an inner volume of 501 . Once defined the "standard crate", knowing the density of a specific food, it is possible to calculate the transported weight. Thus, the functional unit considered in this study is 1 standard crate. Whenever hundreds of other formats are marketed, the considered functional unit is a standard case and the results of this study can be divided by the standard inner volume 501 and proportioned to the maximum replenishment of the other format used in the market, for having a rough measure of impacts. Since crate can be a single-use or multi-use packaging, different parameter settings have been taken into account, such as lifetime and recycling shares, to make a comparison possible.

\subsection{System boundary and description}

Hereafter the system boundaries of each investigated crate, defined according the PCR for crates for food, are described. The comparison of the life cycle was made for the same format (1 FU) for packaging for each material. Other material for the transport in the network system (e.g. pallets) and the content (e.g. apples or carrots), due to the equal inner volume, was not considered in the analysis.

The single-use network involves the manufacturing processes and the transportation activities from the crate production plant to the filling centre, from the filling centre to the distribution centre, from the distribution centre to customers and finally from the latter to the disposal/treatment plant. Plastic is in general not stable against light, heat, etc. but the low content of the additives such as UV absorber and antioxidant has been neglected in the system boundary. This system is represented in Fig. 1.

A plastic crate reused many times represents a multi-use system. Figure 2 shows a multi-use system, including also transports from customers to inspection centre and from inspection centre to filling centre; a cleaning or sanitization treatment is not always required. The treatment of the wastewater, produced by the washing phase before reusing, is included.

In this study, the multi-use was considered and discussed only for plastic crates as the other materials have problems during the sanitization phase which often does not meet the legal requirements requested for packaging in contact with food, implying for this reason a single use of the crate.

Figure 3 shows the system boundaries considered for a corrugated board crate considered in this study. The use of water-based ink for flexo printing and varnish for printing is excluded from the system boundaries due to their negligible impact on the overall system under investigation. The potato starch is used as input product in the corrugated board production.

System boundaries considered for the production of a solid wood crate are represented in Fig. 4. The wood scraps resulting from the manufacturing process are used as input flow in other productions. Scraps are reused as input material for the particle board and MDF manufacturing.

System boundaries considered for the production of MDF crate are represented in Fig. 5. The residues in input come from poplar treatment and solid wood crate production with a proportion of $50 \%$ and $50 \%$, substituting the industrial residues in the existing process "particle board, outdoor use, at plant" of Ecoinvent database (Wernet et al. 2016).

System boundaries considered for the production of particle board crate are represented in Fig. 6. Also, in particle board production, the input of residues occurs. Raw materials of wood chips can be pulpwood, waste wood and residuals.

Geographical boundaries are those of Europe and temporal boundaries are 100 years.

\subsection{Environmental impact categories}

The choice of the environmental factors and impact categories determines the results of the analysis and supports their comparison with other studies and benchmarks (Accorsi et al. 2014).

According to the PCR for crates for food, the following environmental indicator and impact categories were selected (Guinée et al. 2002):

- Global warming potential (GWP), in $\mathrm{kg} \mathrm{CO}_{2}$ equivalents, CML 2001 baseline - January 2016

- Acidification potential (AP), in $\mathrm{kg} \mathrm{SO}_{2}$ equivalents, $\mathrm{CML}$ 2001 non-baseline - January 2016

- Eutrophication potential (EP), in $\mathrm{kg} \mathrm{PO}_{4}{ }^{3-}$ equivalents, CML 2001 baseline - January 2016

- Cumulative energy demand (CED), in MJ

- Human toxicity (HTP), in kg 1,4-DCB equivalents, CML 2001 baseline - January 2016

- Marine toxicity (MTP), in kg 1,4-DCB equivalents, CML 2001 baseline - January 2016

- Terrestrial toxicity (TTP), in kg 1,4-DCB equivalents, CML 2001 baseline - January 2016 


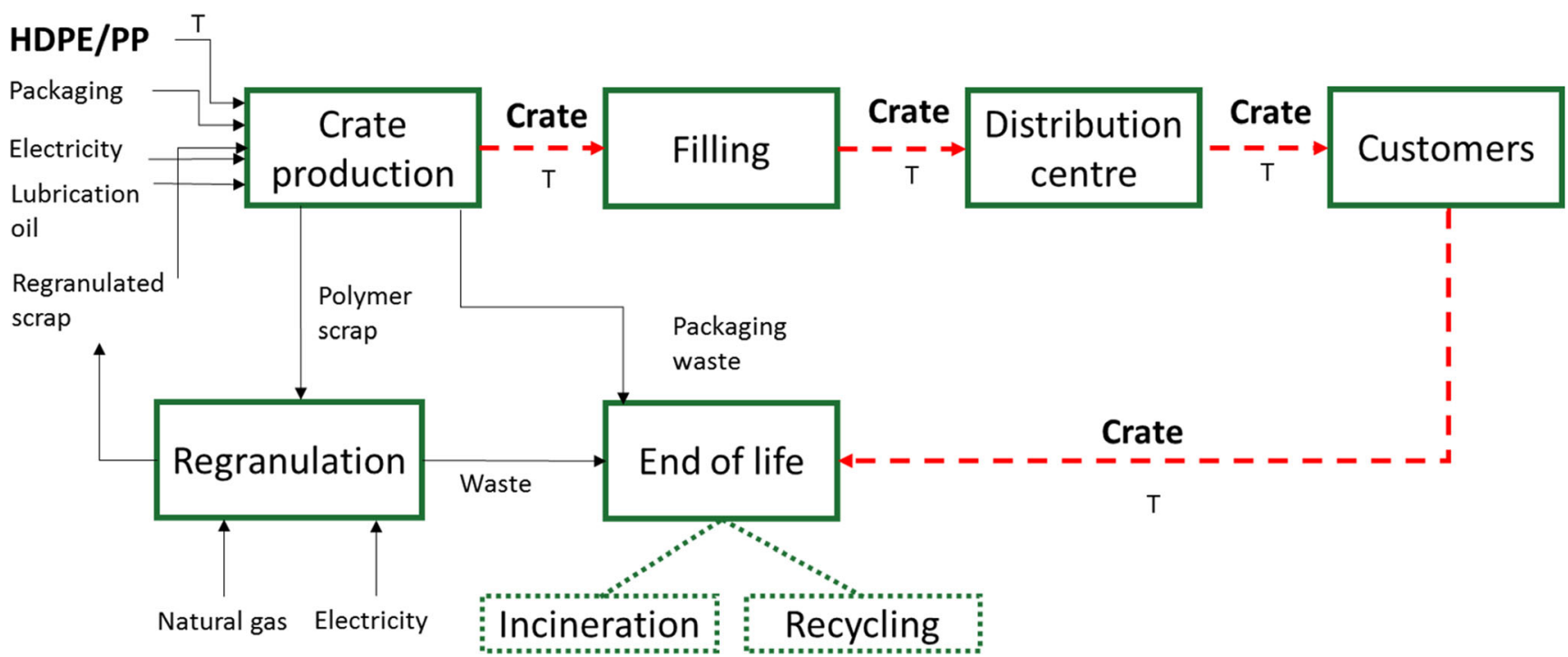

Fig. 1 System boundaries of single-use plastic crate including manufacturing, transport network and end of life

- Freshwater toxicity (FTP), in kg 1,4-DCB equivalents, CML 2001 baseline - January 2016

\subsection{Inventory analysis}

This study is a first of its kind, therefore draws data from several sources. To implement the reliability of the results, a benchmarking activity has been conducted concerning data collected from literature studies. In the case of missing or unreliable data, hypotheses, databases and different scenarios were evaluated. In particular, data for the crate manufacturing were taken from the study carried out by the University of Stuttgart (2007), data for the corrugated board composition from FEFCO analysis (FEFCO 2004) and data for the transport from the network created by Accorsi et al. (2014), as reported in Table 1 and Table 2.

The Life Cycle Inventory (LCI) concerns data collection and calculation procedures and implies as first step compiling the inventory of relevant energy and material inputs and product and by-product outputs. Data are related to the input and the output flows for each process involved in the system boundaries and they are collected for the packaging systems illustrated in Table 1. The collected data for this analysis comes directly from production plants, from literature or from Ecoinvent database. In carrying out such a comprehensive LCA study that considers all the materials commonly used in the crates for food production, problems of data availability were inevitably encountered, above all for primary type, deriving directly from crate producers. In particular, a lack of

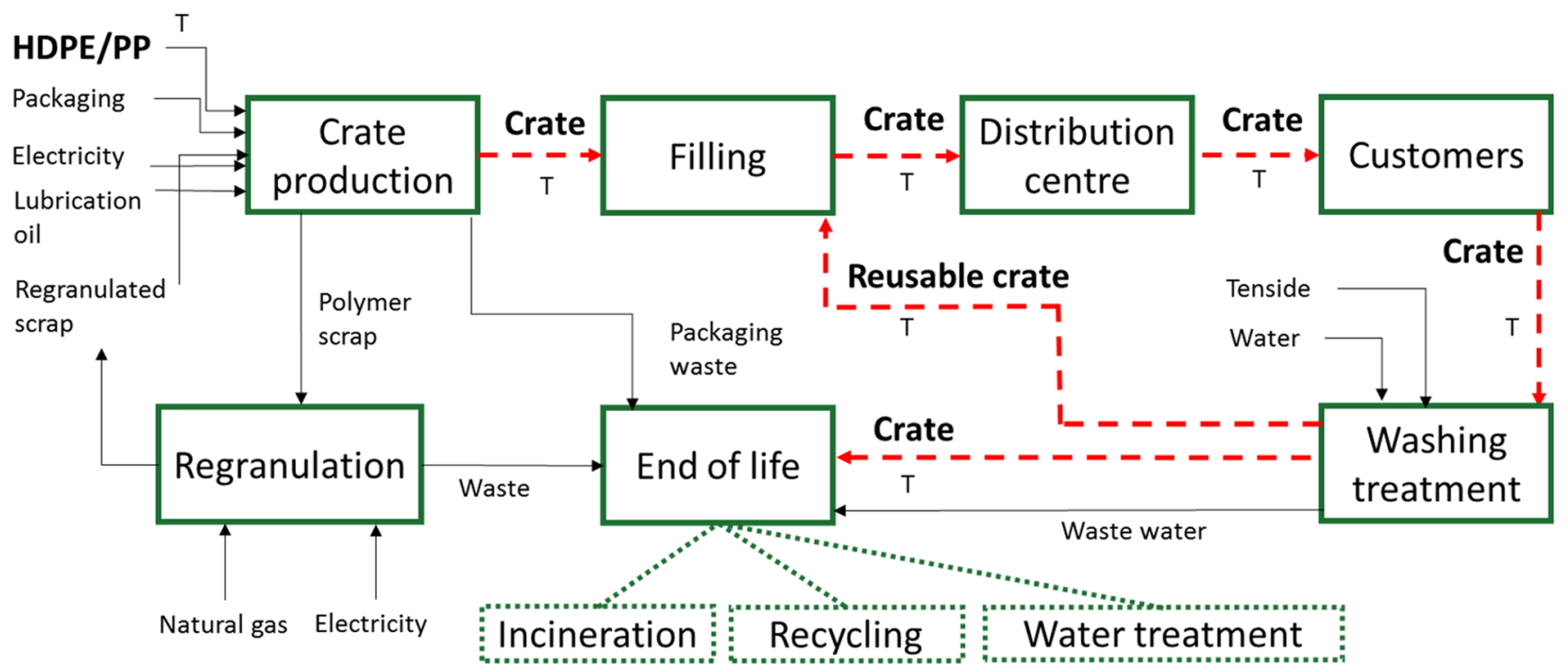

Fig. 2 System boundaries of multi-use plastic crate including manufacturing, transport network, washing treatment and end of life 


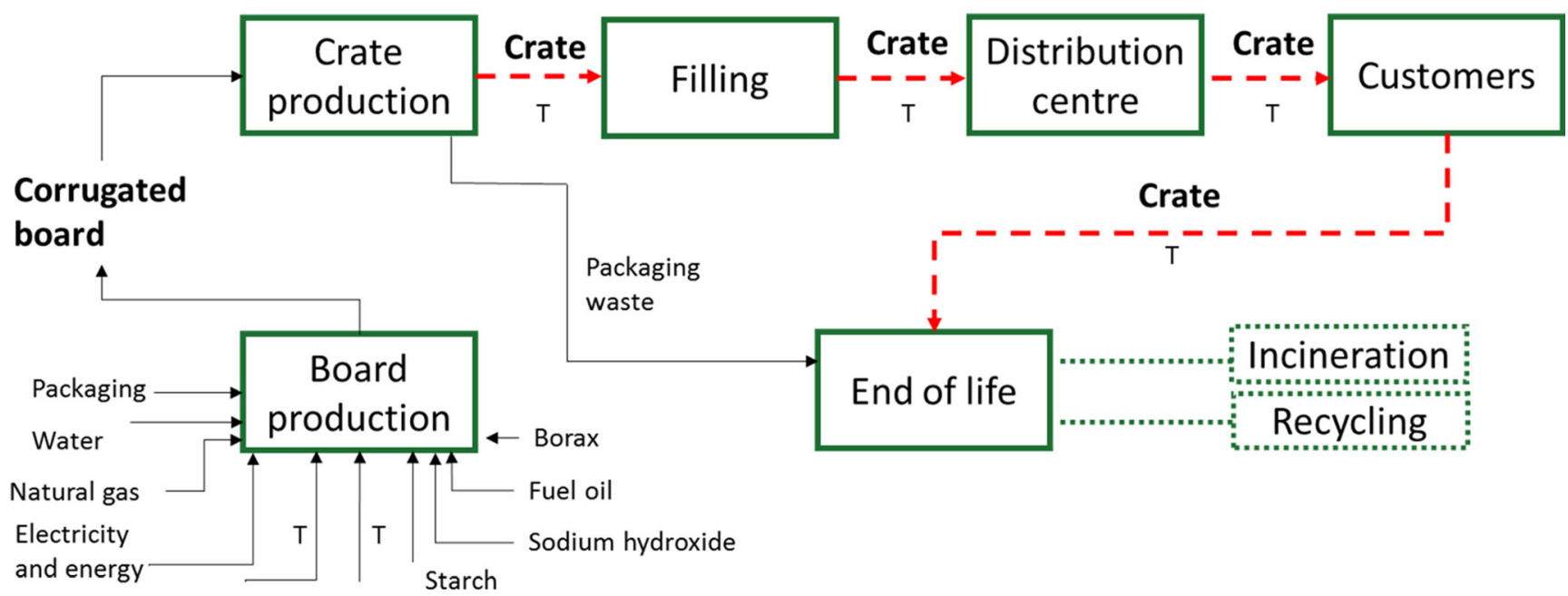

\section{Semichemical Kraftliner paper fluting paper}

Fig. 3 System boundaries of corrugated board crate including manufacturing, transport network and end of life

data occurred for MDF and particle board crates for which a model system was created.

In this study, the weight of MDF and particle board was derived from a direct analysis of material samples retrieved from RILEGNO, the National Consortium for the collection, recovery and recycling of the wooden packaging in Italy, which is the main Italian producer of wooden crates.

The study by Accorsi et al. (2014) was used as a reference for the transport network and for typical distances in the case of lack of data. The data used are presented in Table 2.

\subsection{Plastic crates}

According to the study developed by the University of Stuttgart, the plastic crate analyzed in this study is made of a polymer granulate mix of high-density polyethylene (HDPE) and polypropylene (PP) in the proportion of $58.4 \%$ and $41.6 \%$ by weight, respectively (University of Stuttgart, PE International 2007). HDPE and PP granulate production data derive from the Ecoinvent database. The production of one crate approximately needs $2.0547 \mathrm{~kg}$ of polymer granulate

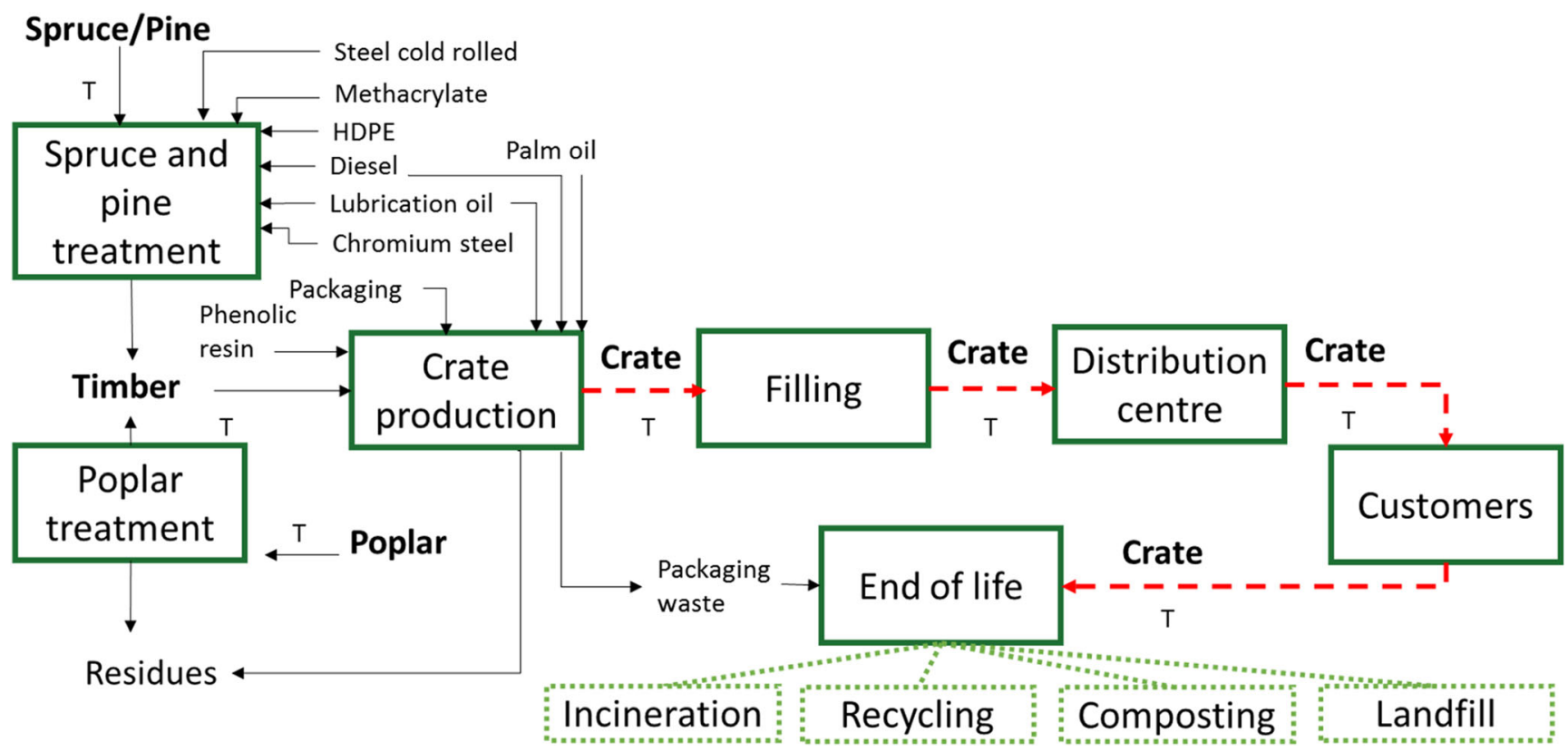

Fig. 4 System boundaries of solid wood crate including manufacturing, transport network and end of life. Incineration includes both incineration at plant and domestic combustion 


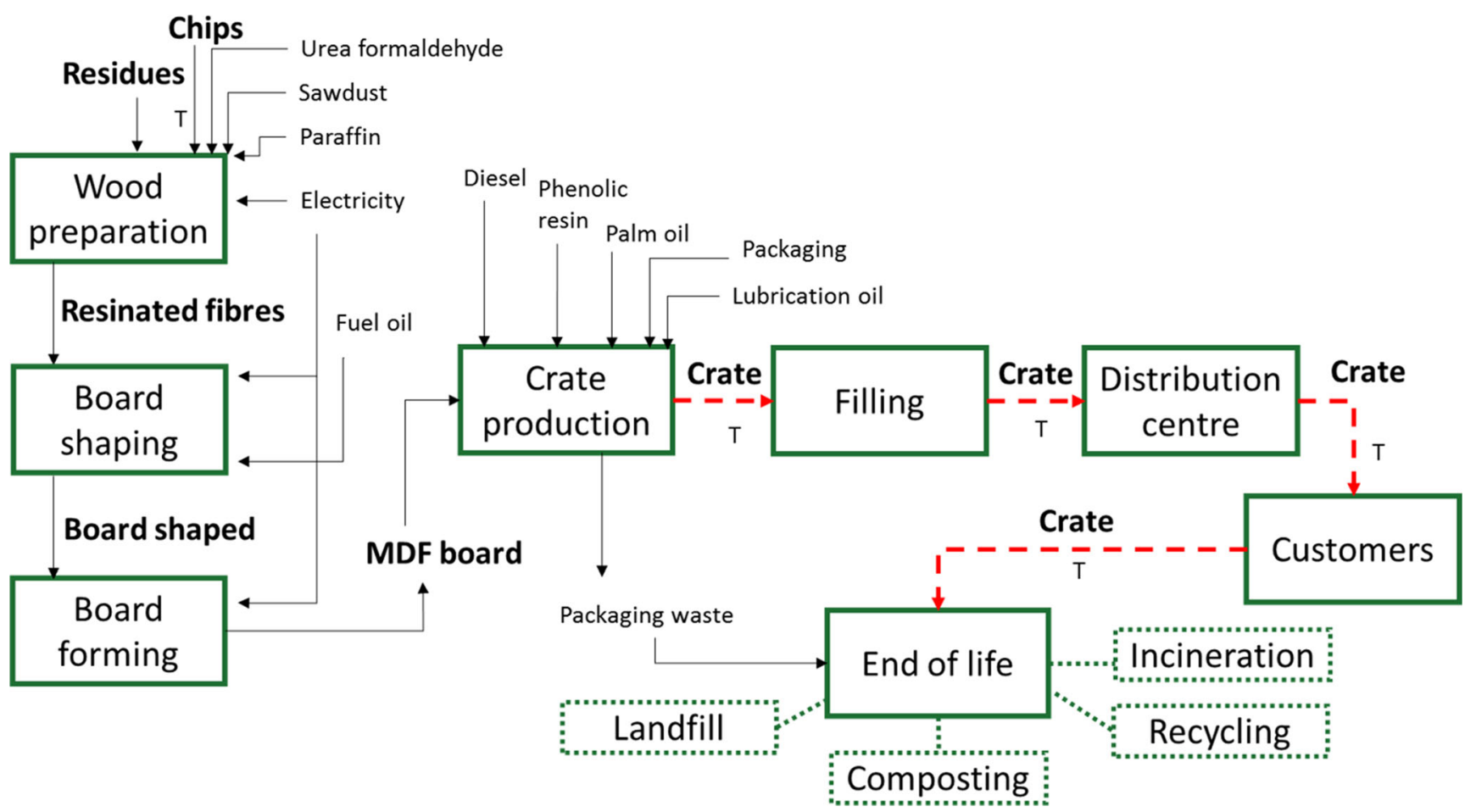

Fig. 5 System boundaries of MDF crate including manufacturing, transport network and end of life. Incineration includes both incineration at plant and domestic combustion

and $1.88 \mathrm{kWh}$ of electric energy. The scrap is supposed to be granulated and recirculated in-house. The single-use plastic crate is used for 1 time during its lifetime and after the use phase is disposed of.
The reusable plastic crate has an average lifetime of 5 years and the number of trips during the lifetime can be set in 50 times, while breakage during the lifetime is less than $1 \%$. These values are approximately confirmed in literature by

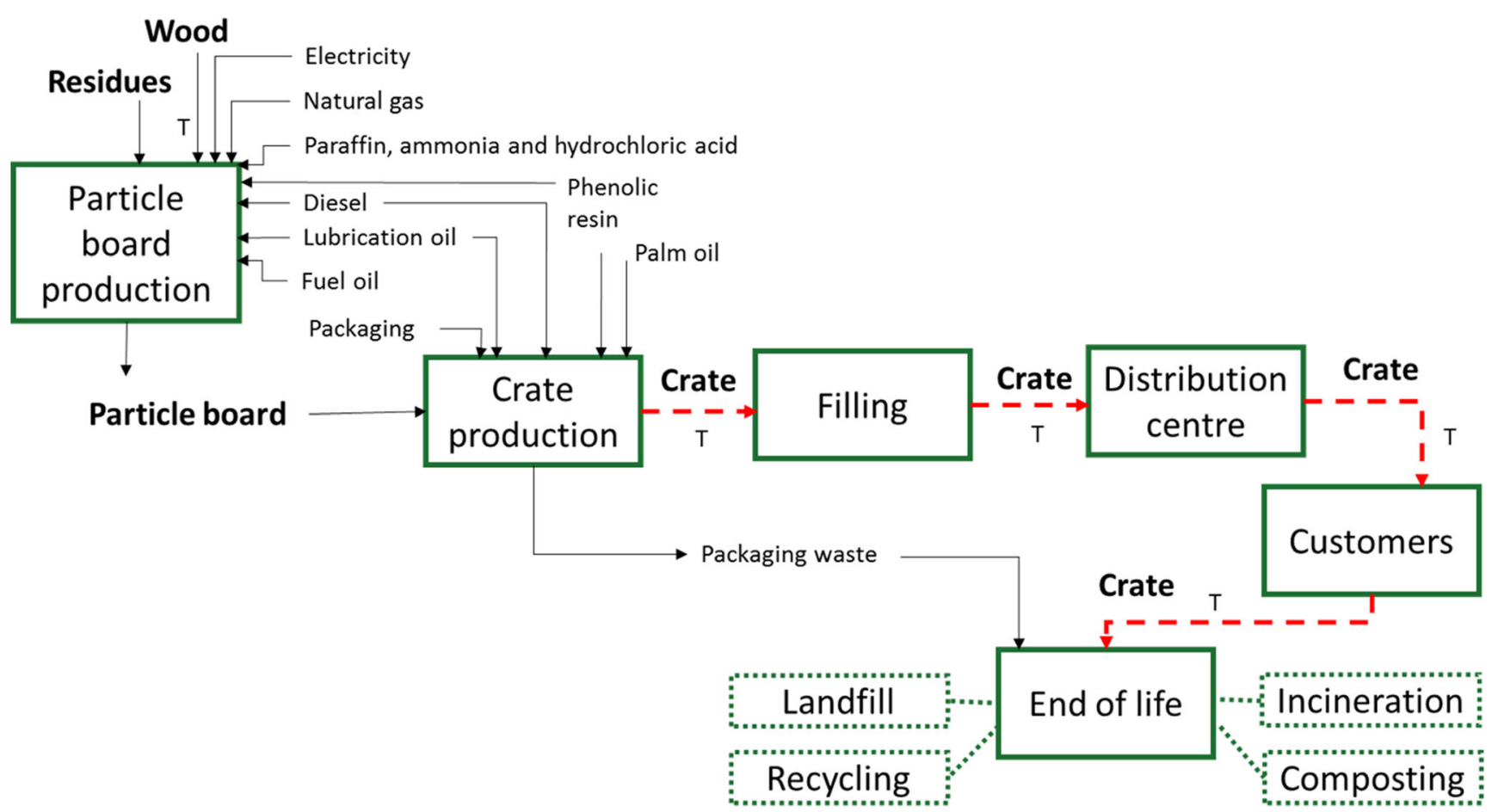

Fig. 6 System boundaries of particle board crate including manufacturing, transport network and end of life. Incineration includes both incineration at plant and domestic combustion 
Table 1 Crates analyzed. The weight data came from University of Stuttgart, PE International 2007 in the case of plastic and solid wood, from FEFCO 2004 for corrugated board crate while in the case of MDF and particle board, it was calculated

\begin{tabular}{llll}
\hline Material & Dimension & Inner volume & Weight \\
\hline Plastic & $400 \times 600 \times 240 \mathrm{~mm}$ & 501 & $2 \mathrm{~kg}$ \\
Corrugated board & $400 \times 600 \times 240 \mathrm{~mm}$ & 501 & $1.086 \mathrm{~kg}$ \\
Solid wood & $400 \times 600 \times 240 \mathrm{~mm}$ & 501 & $0.9 \mathrm{~kg}$ \\
MDF & $400 \times 600 \times 240 \mathrm{~mm}$ & 501 & $1 \mathrm{~kg}$ \\
Particle board & $400 \times 600 \times 240 \mathrm{~mm}$ & 501 & $1.4 \mathrm{~kg}$ \\
\hline
\end{tabular}

the study of Franklin Associate (Franklin Associates 2016). In this study, the comparison of the final results is performed among reusable and not reusable crates too. Since for the reusable plastic crate 50 recycle are considered during its lifetime, the results for the reusable plastic crate will be divided for 50 considering only one cycle such as for the other crates.

During the lifetime of a plastic reusable crate, the following assumptions have been done: a breakage rate of $0.4 \%$, a washing treatment before reuse for the $97.6 \%$ of the multi-way plastic crate, a direct recirculation after the inspection of the remaining $2 \%$. In this study, package waste is allocated to incineration and recycling in the proportions of $7 \%$ and $93 \%$, respectively. Data on energy consumption (natural gas and electricity) for recycling plastic packaging waste originate from Arena et al. (2003), making the assumption that data are similar for a mix of HDPE/PP. Incineration data input derives from Ecoinvent.
In the case of multi-way plastic crates, the wastewater treatment of the water deriving from washing has been included in the analysis using data of University of Stuttgart (2007).

\subsection{Corrugated board crate}

The analyzed corrugated cardboard crate for food delivery is mainly composed of kraft liner paper $(58.6 \%)$ and semichemical fluting (41.4\%) (FEFCO 2004). For kraft liner and semi-chemical fluting paper, data from Ecoinvent have been used after a preliminary comparison with data of FEFCO database. The conversion losses for the sold corrugated product are about $10 \%$ and additional losses to the converted box are assumed about $7 \%$. The corrugated board crate is not reusable after its use phase, so it carries out only one cycle (FEFCO 2015). After its use, the corrugated cardboard crate is disposed to incineration and recycling in the proportions of $22 \%$ and $78 \%$, respectively.

\subsection{Wood crates}

According to an unpublished analysis of the wooden market sector performed by Rilegno, in 2015, 238,341 tons of wooden packages was produced in Italy. Different wooden materials can be used to produce a wood crate for food delivery. In this study, solid wood, MDF and particle board crates are analyzed.

The wood solid crates are composed of a rate of 70\% poplar, $17 \%$ pine and $13 \%$ spruce. The wood treatment has been included in the study and the distance from forestry to peeling or sawing plant was assumed equal to $50 \mathrm{~km}$, according to the available data on the supply chain collected by RILEGNO.
Table 2 Distances of each link of the network. "Transport, lorry 1632t, EURO3" of Ecoinvent database was used as input flow. Data are referred to both reusable and not reusable plastic (for which the link from customers to washing centre does not exist) and for all different types of wood (solid, MDF, particle board). $M$, manufacturing centre, $F$, filling centre, $D$, distribution centre, $C$, customers, $W$, washing centre, $E$, end of life

\begin{tabular}{lllll}
\hline Crate & Link & Value & Unit & Source \\
\hline Plastic & From M to F & 100 & $\mathrm{~km}$ & Accorsi et al. (2014) \\
& From F to D & 100 & $\mathrm{~km}$ & \\
& From D to C & 100 & $\mathrm{~km}$ & \\
& From C to E & 100 & $\mathrm{~km}$ & \\
Corrugated board & From C to W to F & 150 & $\mathrm{~km}$ & \\
& From M to F & 50 & $\mathrm{~km}$ & Accorsi et al. (2014) \\
& From F to D & 100 & $\mathrm{~km}$ & \\
Wood & From D to C & 100 & $\mathrm{~km}$ & \\
& From C to E & 100 & $\mathrm{~km}$ & \\
& From M to F & 100 & $\mathrm{~km}$ & Accorsi et al. (2014) \\
& From F to D & 100 & $\mathrm{~km}$ & \\
& From D to C & 100 & $\mathrm{~km}$ & \\
& From C to incineration & 100 & $\mathrm{~km}$ & Primary data from the sector \\
& From C to landfill & 100 & $\mathrm{~km}$ & \\
& From C to recycling & 221 & $\mathrm{~km}$ & \\
& From C to composting & 100 & $\mathrm{~km}$ & \\
\hline
\end{tabular}


Fig. 7 Comparison between manufacturing results

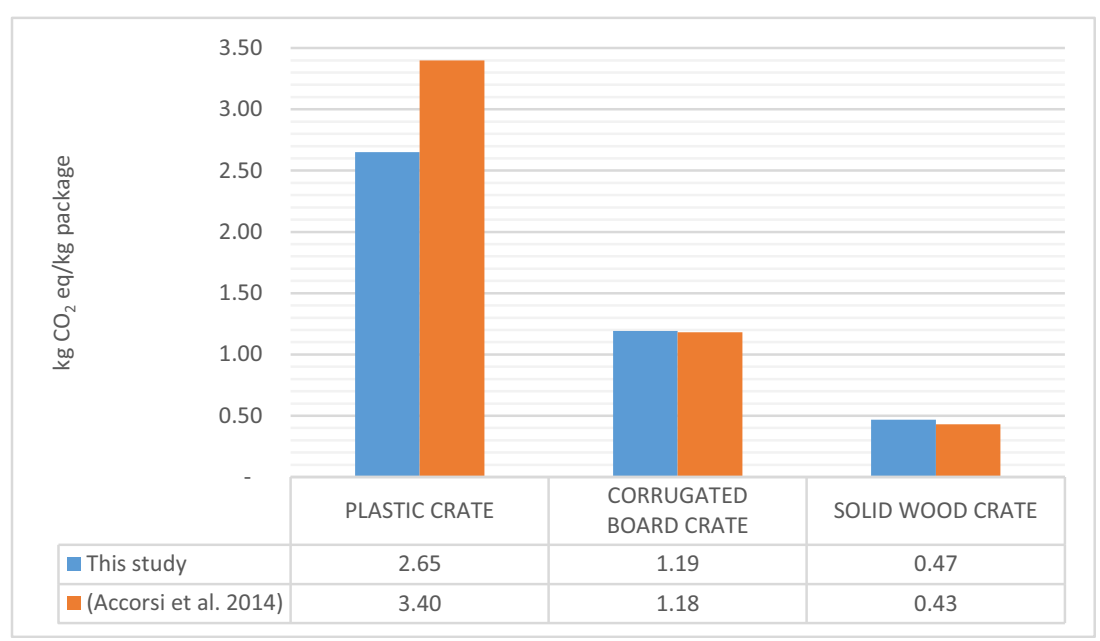

During the wood treatment and the crate manufacturing, a wood scrap is generated and subsequently used in the particle board and MDF board production. During the peeling, around $13 \%$ wood losses occur and during the crate production, an average of $30 \%$ (University of Stuttgart, PE International 2007).

To create the process of the particle board production, the "particle board, outdoor use, at plant" process of Ecoinvent database was used as a reference.

The MDF board process was created according to Rivela et al. (2007). Moreover, for both particleboard and MDF, to realize the crate manufacturing processes, an assumption of a material loss of $7 \%$ was made. The National Trade Association Rilegno has the task to ensure the achievement of the mandatory recovery targets of post-consumer wood packaging and has contributed to reach and overcome the goals set by the legislator (recycling of $35 \%$ ): by now the overall recovery of wood packaging reached at the end of life is close to $60 \%$ of the consumption. In accordance with the sector studies made available by RILEGNO, the end-of-life scenario of the wooden crates are landfill disposal (23\%), waste-to-energy plant (3\%), in-house combustion (24\%), recycling $(41 \%)$ and composting $(9 \%)$. According to Accorsi et al. (2014), the recycling $1 \mathrm{t}$ of veneers consumes $100 \mathrm{kWh}$ of electricity. Data on electricity and water consumption for composting process was adapted from Aziz et al. (2016) and for mechanical treatment in the landfill from Buratti et al. (2015).

\section{Results and discussion}

The results of the study, divided into manufacturing and overall process, and concerning the sensitivity analysis, are summarized in the following.

\subsection{Manufacturing}

The environmental impacts given by the production of $1 \mathrm{~kg}$ of package are given in terms of GWP and, due to the similar hypothesis, a comparison was made with the results obtained by Accorsi et al. (2014) as shown in Fig. 7. The difference in plastic crate results can be associated with the use of HDPE/ PP mix of plastic, the in-house recycling of polymer scrap and the distances to manufacturing plant.

\subsection{Overall process}

All the analyzed impact categories for one crate, within the assumed system boundaries over the total life cycle, result lower for the multi-way plastic crate than for the other packaging systems as reported in Table 3 and in Fig. 8. Despite a slightly higher environmental impact, also the solid wood crate is to be potentially considered a low impact packaging. On the other hand, the single-use plastic crate results to be the worst choice in most of the impact categories, especially due to the high impact of HDPE and PE production and disposal.

In particular, considering the acidification (AP), in the cases of plastic and wooden crates, the major contribution is given by electricity generation and transport emissions whereas for corrugated board crate, the impact is due to base paper production. As a consequence of the impacts of the paper manufacturing, the corrugated board crate turns out to be the worst choice in terms of the eutrophication (EP), due to the impact of emissions to water and land from effluents of the paper mill, and in terms of HTP. The food packaging is designed to minimize the release of toxic substances but due to the temperature, to the food that is into contact with or to other factors, a part of this substance is transferred. Analyzing HTP results, the solid wood material against the plastic and the corrugated board tends to generate a minor amount of human toxic substances. Indeed, the corrugated board crate is subject 
Table 3 Overall process results per impact category

\begin{tabular}{|c|c|c|c|c|c|c|c|}
\hline & & Plastic one way & Plastic multi way & Corrugated board & Solid wood & MDF & Particle board \\
\hline GWP & $\mathrm{kg} \mathrm{CO}_{2}$ eq & 8.79 & 0.30 & 3.09 & 0.51 & 0.83 & 0.81 \\
\hline $\mathrm{AP}$ & $\mathrm{kg} \mathrm{SO}_{2}$ eq & 0.03 & 0.00 & 0.01 & 0.00 & 0.00 & 0.00 \\
\hline EP & $\mathrm{kg} \mathrm{PO}_{4}^{3-}$ eq & 0.00 & 0.00 & 0.00 & 0.00 & 0.00 & 0.00 \\
\hline MTP & $\mathrm{kg} 1,4-\mathrm{DB}_{\mathrm{eq}}$ & 1879.15 & 58.63 & 1407.44 & 207.23 & 151.65 & 305.37 \\
\hline HTP & $\mathrm{kg} 1,4-\mathrm{DB}_{\mathrm{eq}}$ & 1.13 & 0.05 & 1.45 & 0.32 & 0.32 & 0.73 \\
\hline TTP & $\mathrm{kg} 1,4-\mathrm{DB}_{\text {eq }}$ & 0.01 & 0.00 & 0.02 & 0.01 & 0.01 & 0.01 \\
\hline FTP & $\mathrm{kg} 1,4-\mathrm{DB}_{\mathrm{eq}}$ & 0.64 & 0.02 & 0.33 & 0.08 & 0.07 & 0.09 \\
\hline
\end{tabular}

to an easier deterioration whereas the legally guaranteed plastic crate - at high temperature or preserved in the long termcan release toxins, toxic metalloids, etc.

The process contributions to GWP of the multi-use plastic crate were analyzed and presented in Fig. 9, to better understand which life cycle steps influence the results while using a reusable plastic crate. Electricity, transport and material contributions have a certain influence on final results of the reusable plastic crate, that means the multi-use plastic crate is the best solution due to the possibility of being reused during its lifetime, avoiding the high impacts of the production phase, mainly due to the energy request. The transport has an influence on GWP around 41\%, so when a comparative LCA study is performed for these types of packaging, transport cannot be excluded from system boundaries and any limitations about data quality and accuracy shall be checked and transparently declared. For this reason, in this study, the sensitivity analysis is performed and presented in the following chapter, by a specific focus on the variation of the parameter related to transport. Among the other relevant parameters, the raw materials contribute in significant way to final results and specifically about $16 \%$ by HDPE and $12 \%$ by PP. Moreover, another further contribution of about 3\% (1.03\% by PP and $1.74 \%$ by HDPE) is due to the incineration at the end of life of the plastic crate. Even if this contribution is not so significant, a reduction could be achieved by promoting a higher recycling rate.

As general result, all the analyzed impact categories result lower for multi-use plastic crate rather than for other packaging systems but not for the non-renewable energy resources use - and consequently for total energy resources - as presented in Fig. 10. The total CED is composed of the nonrenewable energy resources (fossil, nuclear, primary forest) and the renewable energy resources (biomass, water, wind, geothermal and solar energy) used in the life cycle. The results show that the renewable energy resources in the case of plastic crates are about $3 \%$ while in the other transport system, exceed the $30 \%$ reaching $77.5 \%$ in the case of the solid wood crate. Plastic crate could return better results in case a higher content of recycled materials avoids the use of virgin materials. The use of recycled plastic materials for food packaging is regulated by Regulation EC 282/2008 and considering the Italian legislation in particular, plastic materials obtained from scrap or after use phase cannot be used to produce objects into
Fig. 8 Overall process results per impact category

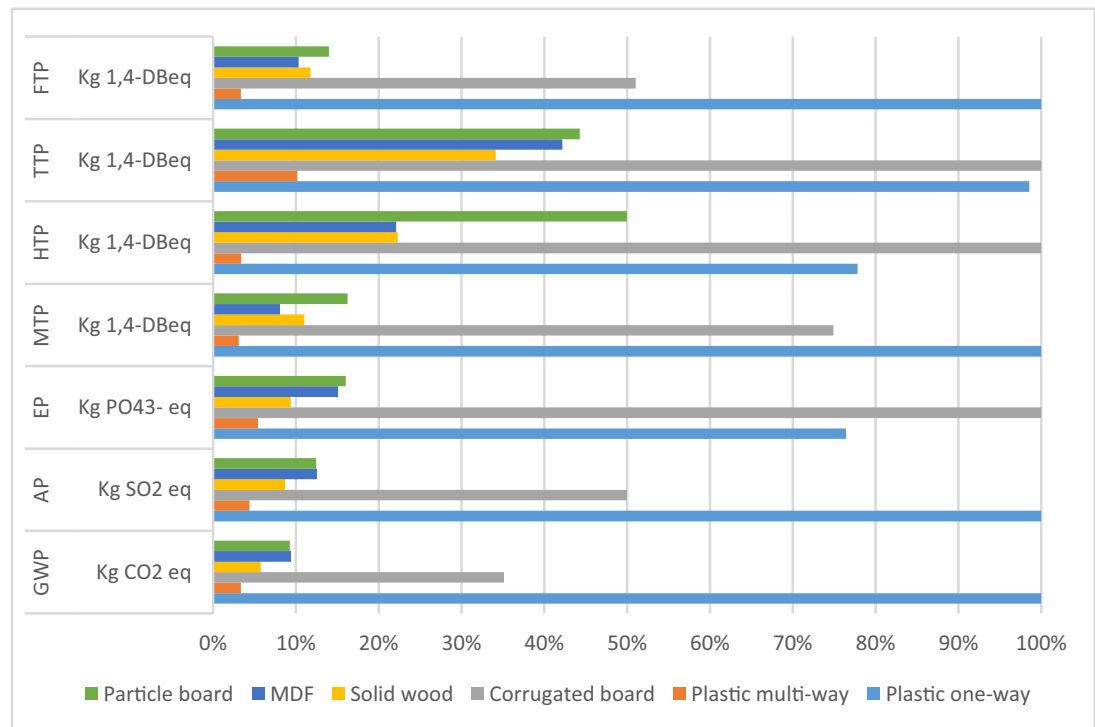


Fig. 9 Process contributions to GWP of reusable plastic crate

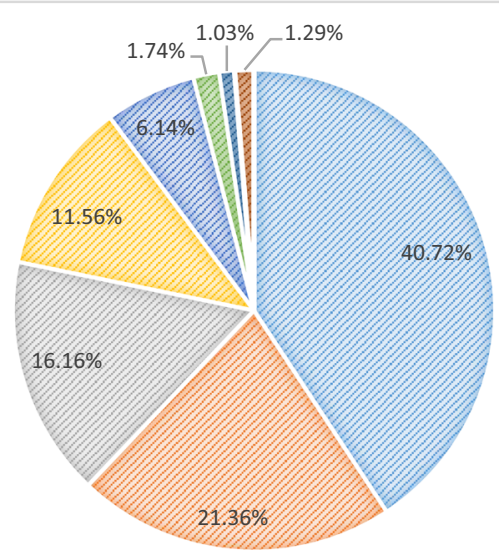

" transport, lorry 16-32t, EURO3 - RER

- electricity, medium voltage, at grid - IT

polyethylene, HDPE, granulate, at plant - RER

- polypropylene, granulate, at plant RER

- natural gas, burned in power plant - IT

- disposal, polyethylene, $0.4 \%$ water, to municipal incineration $-\mathrm{CH}$

- disposal, polypropylene, $0.4 \%$ water to municipal incineration - $\mathrm{CH}$

- other processes direct contact with food, but recycled plastics can be used if a barrier material is inserted, avoiding the direct contact to food. Anyway, the recycled plastic materials are generally used to produce objects, also crates, not into contact with food (Arena et al. 2003; Xie et al. 2013).

\subsection{Sensitivity analysis}

The results of a LCA study can be affected by several uncertainties in the sources and input data. A tool to deal with parameter uncertainty and variability of data and sources in both the inventory and the impact assessment phases is a probabilistic simulation, called sensitivity analysis (Huijbregts 1998). In this study, in order to evaluate the influence of this uncertainty on final results, a sensitivity analysis was performed by varying:

- Transport network option: a variation of the transport network system increasing and decreasing the distances of the $\pm 5 \%, \pm 15 \%$ and $\pm 25 \%$ was simulated

- EoL scenario: a variation of the $\%$ wherewith packages is disposed of was considered

Fig. 10 Use of renewable and non-renewable energy resources for the different packaging systems
On the basis of the general environmental results previously presented, the sensitivity analysis was carried out for the first and the second most performing materials (multi-use plastic and solid wood crates), considering the transport parameter variation. In Fig. 11, the GWP results concerning the sensitivity analysis for the distance variation are illustrated. The figure shows a higher influence of the transport distance for the reusable plastic crate than for the solid wood one. However, for a solid wood crate, it is possible to appreciate a constant increase of about $0.67 \%$ of the GWP100 for each $5 \%$ increase of the distances. Moreover, this applied also to the reusable plastic crate with a linear increase of about $2 \%$. According to these results, data and hypothesis made initially are to be considered proper for this first analysis.

In particular, this linear correlation of increase of about $2 \%$ should be considered when the logistics of collection and return of the crates must be planned, in order to minimize the impacts, so as not to lose the environmental advantage compared with the single-use disposable crate.

The high impact of transport in the Italian scenario is due to the fact that most of the producers of crates are located in southern Italy, often near agricultural areas and the use of

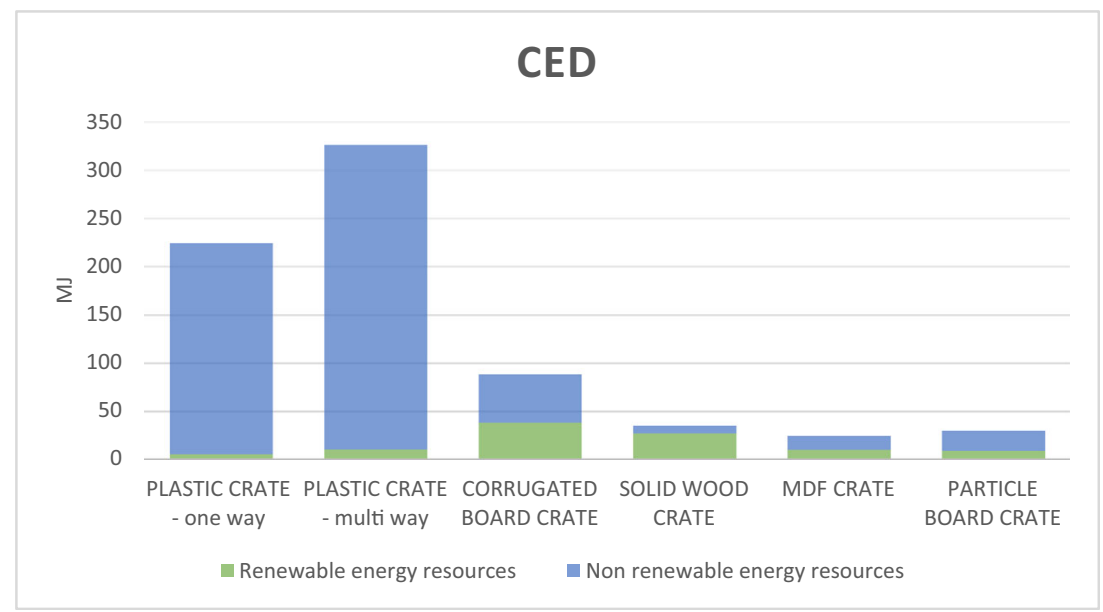




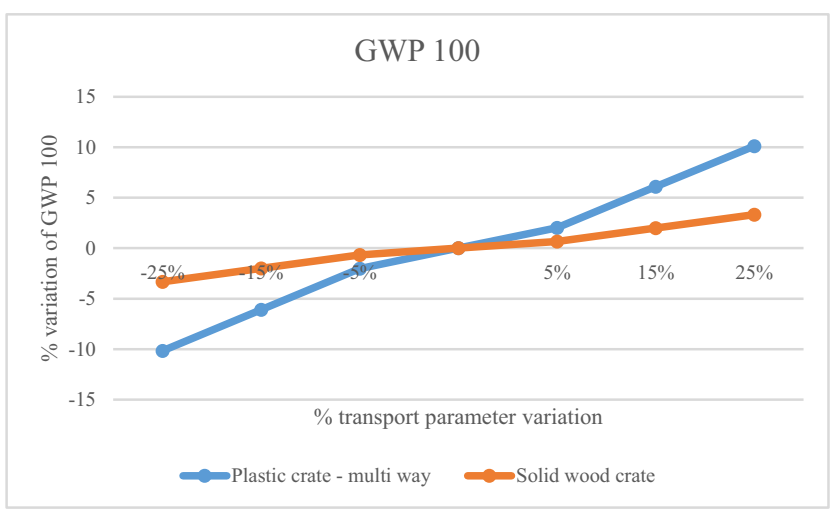

Fig. 11 Influence of transport parameter variation on GWP

the crate up for the transport of food in large-scale distribution in northern Italy implies several hundred $\mathrm{km}$ for transport. A simple product like a box therefore requires a short chain between production and use in order to minimize its impact.

On the other side, the different EoL scenarios are investigated only for the plastic crate because data relative to the wooden crate which comes from sector studies of the category association (RILEGNO) were considered proper and not to be further tested. The sensitivity analysis performed on EoL scenarios, represented in Fig. 12, shows that increasing the percentage of plastic crate recycling, the resulted GWP proportionally decreases. A significant decrease (around 14.7\%) in the GWP is obtained increasing the recycling from 0 to $100 \%$. As previously said, due to the legislation regarding food contact materials, the recycled plastic is used for other application. However, the hypothesis made initially was suitable for plastic crate considering a percentage of scrap during the recycling which anyway is disposed by incineration.

\section{Conclusion}

Since packaging is one of the most relevant waste sources, attention to packaging materials, design and management is warranted, especially in sectors where packaging is functional to handling and transportation, as for the crates for food considered in this study. This paper analyzed, evaluated and compared the environmental performance of the crates for food delivery, considering the material most commonly used: plastic crate both multi way and one way, corrugated board crate, solid wood crate of different material types, particle board and MDF wood. The life cycle assessment methodology was used and applied and due to the exhaustive variety of analyzed material and the reached outcomes, this study should be considered the first of its kind. All the results were referred to the functional unit, 1 crate with an external dimension of $600 \times 400 \times$ $240 \mathrm{~mm}$ and an inner volume of 501 considering also the number of cycles during the lifetime. Several impact categories were analyzed: global warming potential, eutrophication potential, acidification potential, human toxicity, marine ecotoxicity, terrestrial ecotoxicity and freshwater ecotoxicity.

The results derived by the LCA have shown that the multi-use plastic crate has better environmental performance if there is a recovery system allowing reusing the crates many times. The reason is that the high impacts due to the production crate are avoided. Without a recovery system that allows to collect and recuse the plastic crate, the use of the plastic crate must be avoided. In this study, a reuse of 50 times was hypothesized. Fewer reuses significantly reduce the environmental advantage of multi-use crates.

Among the one-way crates, the solid wooden ones resulted to be the less impacting in most of the selected impact categories. This analysis showed that the best results for wooden crates are reached when wood is used as a raw material rather than a processed material, showing that the best performance is reached by the solid wood crate. Moreover, the corrugated board material is highly affected by a significant impact generated during the paper production, resulting in the less
Fig. 12 Effect of EoL parameter variation on GWP

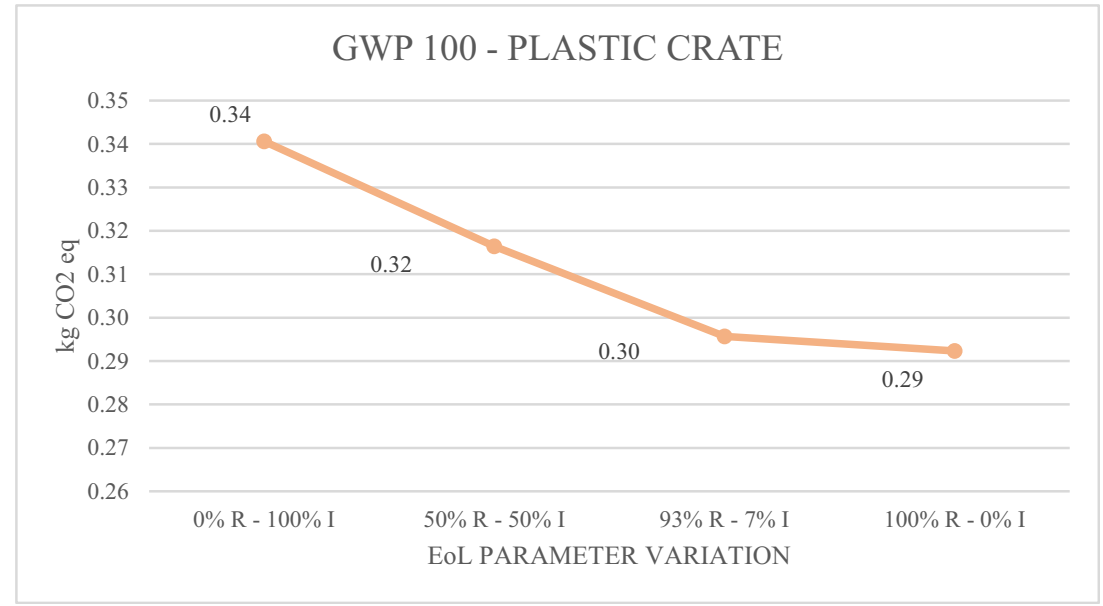


environmentally sound choice among the crates under investigation.

To evaluate the influence of data uncertainty on the final results, a sensitivity analysis was performed: transport distances data from literature and EoL scenarios were examined to quantify their influence on final results.

The sensitivity analysis allowed to identify the distances of the transport network as one of the critical parameters. The linear correlation of increase of GWP together with the increase of the distance suggests that the logistics of collection and return of the crates must be planned minimizing distances; otherwise, the environmental advantage of not using input material for the production of a new disposable crate is lost or significantly reduced. Transport has a great influence on results and it is suggested that in order to confirm the reliability of the results and support the final conclusion, primary data should be collected and processed.

Moreover, the final results show that the impacts related to wood crate are more stable variating the transport distances; therefore, it is important in performing an LCA to collect more accurate data, preferentially primary data, on plastic crates than on wood crates.

The most significant outcomes of this paper were summarized and used to develop a PCR for crates into contact with food in order to set specific requirement for LCA applied to these products and to support the development of environmental labels and claims, such as the EPD of the International EPD System (IES). The methodology for developing a PCR refers to ISO 14025. Due to the lack of specific rules, the functional unit is a critical aspect to be defined for crates for food, considering that one of the more impacting phase, the transport system, has to take into consideration different sizes, materials and contents. Also, the choice of system boundaries is critical if a comparison between different material is investigated by the LCA methodology. Starting from this acquired knowledge, then the interest may be to test the results through the analysis of the industrial sector defining the methodology for the development of a Sector EPD according to the rules of the International EPD System (Strazza et al. 2010).

The results of this study contributed to real understanding and representation of the significant environmental impacts of the production, the network system and the end of life of different packaging systems, allowing a correct identification of the functional unit and the system boundaries.

Finally, this study included the system boundaries of wood materials, the use scrap from another process (e.g. MDF and particle board), allowing the definition of possible allocation method.

A harmonization of the main parameter and calculation rules for the LCA studies regarding the crates for food can be realized and different systems can be compared in a consistent way, by applying the requirements defined in the PCR 2018:02 "Crates for food", nowadays registered and publicly available.
Acknowledgements Open access funding provided by Università degli Studi di Genova within the CRUI-CARE Agreement.

Open Access This article is licensed under a Creative Commons Attribution 4.0 International License, which permits use, sharing, adaptation, distribution and reproduction in any medium or format, as long as you give appropriate credit to the original author(s) and the source, provide a link to the Creative Commons licence, and indicate if changes were made. The images or other third party material in this article are included in the article's Creative Commons licence, unless indicated otherwise in a credit line to the material. If material is not included in the article's Creative Commons licence and your intended use is not permitted by statutory regulation or exceeds the permitted use, you will need to obtain permission directly from the copyright holder. To view a copy of this licence, visit http://creativecommons.org/licenses/by/4.0/.

\section{References}

Abejón R, Bala A, Vázquez-Rowe I, Aldaco R, Fullana-i-Palmer P (2020) When plastic packaging should be preferred: life cycle analysis of packages for fruit and vegetable distribution in the Spanish peninsular market. Resour Conserv Recycl 155:104666. https://doi. org/10.1016/j.resconrec.2019.104666

Accorsi R, Cascini A, Cholette S, Manzini R, Mora C (2014) Economic and environmental assessment of reusable plastic containers: a food catering supply chain case study. Int J Prod Econ 152:88-101. https://doi.org/10.1016/j.ijpe.2013.12.014

Albrecht S, Brandstetter P, Beck T, Fullana-i-Palmer P, Grönman K, Baitz M, Deimling S, Sandilands J, Fischer M (2013) An extended life cycle analysis of packaging systems for fruit and vegetable transport in Europe. Int J Life Cycle Assess 18:1549-1567. https:// doi.org/10.1007/s11367-013-0590-4

Arena U, Mastellone ML, Perugini F (2003) Life cycle assessment of a plastic packaging recycling system. Int J Life Cycle Assess 8:92-98

Aziz R, Chevakidagarn P, Danteravanich S (2016) Life cycle sustainability assessment of community composting of agricultural and agro industrial wastes. J Sustain Sci Manag 11:57-69

Blanco I, Ingrao C, Siracusa V (2020) Life-cycle assessment in the polymeric sector: a comprehensive review of application experiences on the Italian Scale. Polymers 12:1212. https://doi.org/10.3390/ polym 12061212

Buratti C, Barbanera M, Testarmata F, Fantozzi F (2015) Life cycle assessment of organic waste management strategies: an Italian case study. J Clean Prod 89:125-136. https://doi.org/10.1016/j.jclepro. 2014.11.012

Del Borghi A (2013) LCA and communication: environmental product declaration. Int J Life Cycle Assess 18:293-295. https://doi.org/10. 1007/s11367-012-0513-9

Del Borghi A, Gaggero PL, Gallo M, Strazza C (2008) Development of PCR for WWTP based on a case study. Int J Life Cycle Assess 13: 512-521. https://doi.org/10.1007/s11367-008-0023-y

Del Borghi A, Gallo M, Strazza C, Del Borghi M (2014) An evaluation of environmental sustainability in the food industry through Life Cycle Assessment: the case study of tomato products supply chain. J Clean Prod 78:121-130. https://doi.org/10.1016/j.jclepro.2014.04.083

Del Borghi A, Gallo M, Magrassi F (2016) Glass packaging design and life cycle assessment: deep review and guideline for future developments. In: Reference module in food science. Elsevier

Detzel A, Mönckert J (2009) Environmental evaluation of aluminium cans for beverages in the German context. Int J Life Cycle Assess 14:70-79. https://doi.org/10.1007/s11367-008-0057-1

Dobon A, Cordero P, Kreft F, Østergaard SR, Robertsson M, Smolander M, Hortal M (2011a) The sustainability of communicative 
packaging concepts in the food supply chain. A case study: part 1 . Life cycle assessment. Int J Life Cycle Assess 16:168-177. https:// doi.org/10.1007/s11367-011-0257-y

Dobon A, Cordero P, Kreft F, Østergaard SR, Antvorskov H, Robertsson M, Smolander M, Hortal M (2011b) The sustainability of communicative packaging concepts in the food supply chain. A case study: part 2. Life cycle costing and sustainability assessment. Int J Life Cycle Assess 16:537-547. https://doi.org/10.1007/s11367-0110291-9

European Parliament (1994) Directive 94/62/EC of 20 December 1994 on packaging and packaging waste

European Parliament (2004) Regulation (EC) No 1935/2004 of the European parliament and of the council

Eurostat (2017) Packaging waste statistics - statistics explained. http://ec. europa.eu/eurostat/statistics-explained/index.php/Packaging _ waste_statistics. Accessed 27 Mar 2017

FEFCO (2004) Corrugated Board Boxes and Plastic Container Systems: an analysis of costs and eco-costs

FEFCO (2015) European database for corrugated board life cycle studies

Franklin Associates (2016) Comparative life cycle assessment of reusable plastic containers and display-and non-display-ready corrugated containers used for fresh produce applications

Guinée JB, Gorrée M, Heijungs R, Huppes G, Kleijn R, Koning A de, Oers L van, Wegener Sleeswijk A, Suh S, Udo de Haes HA, Bruijn H de, Duin R van, Huijbregts MAJ (2002) Handbook on life cycle assessment. Operational guide to the ISO standards. I: LCA in perspective. IIa: Guide. IIb: Operational annex. III: Scientific background. Kluwer Academic Publishers, Dordrecht, p 692. CML-IA Characterisation Factors 2016 available at: https://www. universiteitleiden.nl/en/research/research-output/science/cml-iacharacterisation-factorss

Hanssen OJ, Rukke E-O, Saugen B, Kolstad J, Hafrom P, von Krogh L, Raadal HL, Rønning A, Wigum KS (2007) The environmental effectiveness of the beverage sector in Norway in a Factor 10 perspective. Int J Life Cycle Assess 12:257-265. https://doi.org/10.1065/ lca2007.05.329

Huijbregts MAJ (1998) Application of uncertainty and variability in LCA. Int J Life Cycle Assess 3:273. https://doi.org/10.1007/ BF02979835

Humbert S, Rossi V, Margni M, Jolliet O, Loerincik Y (2009) Life cycle assessment of two baby food packaging alternatives: glass jars vs. plastic pots. Int J Life Cycle Assess 14:95-106. https://doi.org/10. 1007/s11367-008-0052-6

Ibáñez-Forés V, Pacheco-Blanco B, Capuz-Rizo SF, Bovea MD (2016) Environmental product declarations: exploring their evolution and the factors affecting their demand in Europe. J Clean Prod 116:157169. https://doi.org/10.1016/j.jclepro.2015.12.078

Ingrao C, Lo Giudice A, Bacenetti J, Mousavi Khaneghah A, Sant'Ana AS, Rana R, Siracusa V (2015a) Foamy polystyrene trays for freshmeat packaging: life-cycle inventory data collection and environmental impact assessment. Food Res Int 76:418-426. https://doi. org/10.1016/j.foodres.2015.07.028

Ingrao C, Tricase C, Cholewa-Wójcik A, Kawecka A, Rana R, Siracusa V (2015b) Polylactic acid trays for fresh-food packaging: a Carbon Footprint assessment. Sci Total Environ 537:385-398. https://doi. org/10.1016/j.scitotenv.2015.08.023

Ingrao C, Gigli M, Siracusa V (2017) An attributional Life Cycle Assessment application experience to highlight environmental hotspots in the production of foamy polylactic acid trays for freshfood packaging usage. J Clean Prod 150:93-103. https://doi.org/10. 1016/j.jclepro.2017.03.007

ISO (2006a) ISO 14040:2006: Environmental management - Life Cycle Assessment - principles and framework. https://www.iso.org/ standard/37456.html. Accessed 5 June 2020
ISO (2006b) ISO 14044:2006: Environmental management - Life Cycle Assessment - principles and framework. https://www.iso.org/ standard/38498.html. Accessed 5 June 2020

Koskela S, Dahlbo H, Judl J, Korhonen MR, Niininen M (2014) Reusable plastic crate or recyclable cardboard box? A comparison of two delivery systems. J Clean Prod 69:83-90. https://doi.org/10.1016/j. jclepro.2014.01.045

Licciardello F (2017) Packaging, blessing in disguise. Review on its diverse contribution to food sustainability. Trends Food Sci Technol 65:32-39. https://doi.org/10.1016/j.tifs.2017.05.003

Magrassi F, Del Borghi A, Gallo M et al (2016) Optimal planning of sustainable buildings: integration of life cycle assessment and optimization in a decision support system (DSS). Energies 9:490. https://doi.org/10.3390/en9070490

Marsh K, Bugusu B (2007) Food Packaging? Roles, materials, and environmental issues. J Food Sci 72:R39-R55. https://doi.org/10.1111/j. 1750-3841.2007.00301.x

PCR 2018:02 (2018) Crates for food, version 1.22. https://www. environdec.com/PCR/Detail/?Pcr=12799. Accessed 5 June 2020

Restuccia D, Spizzirri UG, Parisi OI, Cirillo G, Curcio M, Iemma F, Puoci F, Vinci G, Picci N (2010) New EU regulation aspects and global market of active and intelligent packaging for food industry applications. Food Control 21:1425-1435. https://doi.org/10.1016/j. foodcont.2010.04.028

Rivela B, Moreira MT, Feijoo G (2007) Life cycle inventory of medium density fibreboard. Int J Life Cycle Assess 12:143-150. https://doi. org/10.1065/lca2006.12.290

Robertson GL (2012) Food packaging: principles and practice, third edition. CRC Press. https://www.crcpress.com/Food-PackagingPrinciples-and-Practice-Third-Edition/Robertson/p/book/ 9781439862414. Accessed 27 Mar 2017

Robertson K, Garnham M, Symes W (2014) Life cycle carbon footprint of the packaging and transport of New Zealand kiwifruit. Int J Life Cycle Assess 19:1693-1704. https://doi.org/10.1007/s11367-0140775-5

Siracusa V, Ingrao C, Lo Giudice A, Mbohwa C, Dalla Rosa M (2014) Environmental assessment of a multilayer polymer bag for food packaging and preservation: an LCA approach. Food Res Int 62: 151-161. https://doi.org/10.1016/j.foodres.2014.02.010

Strazza C, Del Borghi A, Blengini GA, Gallo M (2010) Definition of the methodology for a Sector EPD (Environmental Product Declaration): case study of the average Italian cement. Int J Life Cycle Assess 15:540-548. https://doi.org/10.1007/s11367-0100198-x

Strazza C, Del Borghi A, Gallo M (2013) Development of specific rules for the application of life cycle assessment to carbon capture and storage. Energies 6:1250-1265. https://doi.org/10.3390/en6031250

University of Stuttgart, PE International (2007) The sustainability of packaging systems for fruit and vegetable transport in Europe based on life-cycle-analysis

von Falkenstein E, Wellenreuther F, Detzel A (2010) LCA studies comparing beverage cartons and alternative packaging: can overall conclusions be drawn? Int J Life Cycle Assess 15:938-945. https://doi. org/10.1007/s11367-010-0218-X

Wernet G, Bauer C, Steubing B, Reinhard J, Moreno-Ruiz E, Weidema B (2016) The ecoinvent database version 3 (part I): overview and methodology. Int J Life Cycle Assess 21:1218-1230. https://doi. org/10.1007/s11367-016-1087-8

Xie M, Qiao Q, Sun Q, Zhang L (2013) Life cycle assessment of composite packaging waste management - a Chinese case study on aseptic packaging. Int J Life Cycle Assess 18:626-635. https://doi. org/10.1007/s11367-012-0516-6

Publisher's note Springer Nature remains neutral with regard to jurisdictional claims in published maps and institutional affiliations. 